Archive for

Organic Chemistry

Arkivoc 2019, part iv, 69-79

\title{
3-Alkylated indoles by reduction of sulfonyl indoles under flow chemical conditions
}

\author{
Elena Chiurchiù, Alessandro Palmieri,* and Marino Petrini* \\ School of Science and Technology, Chemistry Division, Università di Camerino, via S. Agostino, 1 \\ I-62032 Camerino, Italy \\ Email: alessandro.palmieri@unicam.it, marino.petrini@unicam.it
}

Dedicated to Professor Stephen Hanessian in recognition of his contribution to organic synthesis

Received 01-18-2019

Accepted 03-07-2019

Published on line 03-12-2019

\section{Abstract}

Reduction of 3-(1-arylsulfonylalkyl) indoles (sulfonyl indoles) using polymer-supported sodium borohydride under flow chemical conditions allows an efficient synthesis of 3-alkylindoles with a notable waste minimization and reduced solvent consumption. The flow conditions can be also applied to the synthesis of sulfonyl indoles which can be obtained by a three-component coupling of indoles with aldehydes and $p$ toluenesulfinic acid. Using the two-step flow chemical approach, 3-alkylindoles can be directly obtained from their remote indole and aldehyde precursors.

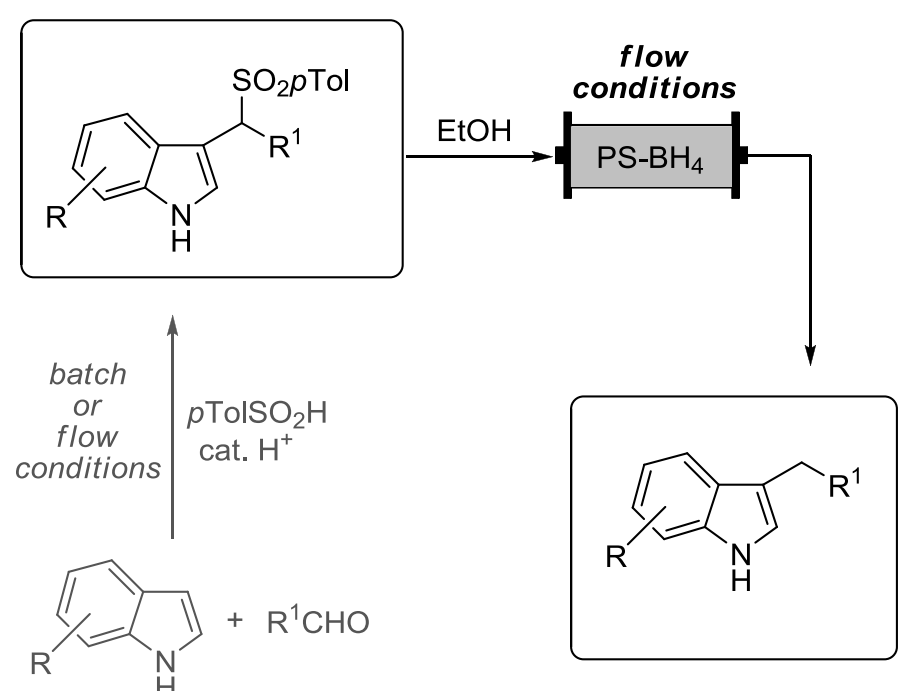

Keywords: Alkylation, flow chemistry, one-pot process, reduction, sulfonyl indoles 


\section{Introduction}

Indole functionalization by electrophilic substitution is a widespreadly used approach to introduce simple or functionalized frameworks in this heteroaromatic system. Friedel-Crafts $(\mathrm{F}-\mathrm{C})$ based procedures usually involve the utilization of various reagents such as acyl halides or electron-poor olefins which electrophilic character can be suitably enhanced by Brønsted or Lewis acid catalysis. ${ }^{1-5}$ Alkylation of indoles exploiting the classical $\mathrm{F}-\mathrm{C}$ conditions is usually hampered by the known limitations pertaining to many electron rich heterocyclic derivatives. ${ }^{6}$ The direct utilization of alkyl halides in acid catalyzed procedures is featured by moderate yields and formation of variable amount of bisalkylated derivatives. ${ }^{7}$ Electrophilic addition of unsaturated derivatives such as terminal alkynes to indoles can be used for the preparation of 3-alkylindoles. In one of these protocols the alkenylindole preliminarily formed upon the $\operatorname{In}(\mathrm{III})$-catalyzed $\mathrm{F}-\mathrm{C}$ reaction of the alkyne with the indole is reduced by diphenylmethylsilane. ${ }^{8}$ The reducing agent can be avoided using a Rucomplex catalyst which oxidizes the alkyne into a ketone and after the $\mathrm{F}-\mathrm{C}$ reaction with the indole reduces the indolenine intermediate formed. ${ }^{9}$ Ketones can be directly used for the preparation of 3-alkylindoles but obviously a silane reducing agent must be present in the reaction mixture. ${ }^{10-11}$ Modern procedures for the alkylation of indoles employ primary and secondary alcohols as reactants in metal redox catalyzed processes, ${ }^{12-14}$ or secondary alcohols in metal-free redox chain reactions. ${ }^{15}$ Finally a successful method using primary and secondary amines in a Ru-catalyzed process is available for the synthesis of 3-alkylindoles. ${ }^{16} \mathrm{~A}$ common feature of all the above cited procedures using alkynes, alcohols, amines and carbonyl derivatives as reactants is the formation of an alkylideneindolenine intermediate 1 which by final regioselective reduction leads to the target 3 -alkylindole compound $\mathbf{2}$ (Scheme 1).

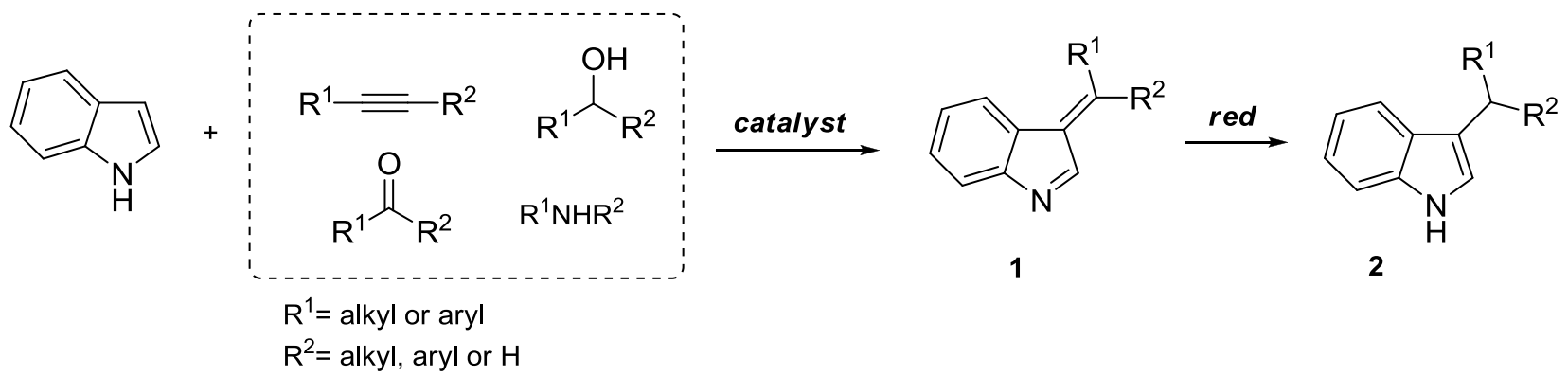

Scheme 1. General strategy for the synthesis of 3-alkylindoles.

Alkylideneindolenines of type $\mathbf{1}$ act as vinylogous imino derivatives and are known intermediates in several processes leading to the synthesis of 3 -functionalized indole derivatives via conjugate addition of various nucleophilic species. Because of the limited stability of intermediates $\mathbf{1}$, these reactive electrophilic species are usually generated in situ from bench stable precursors following the strategy depicted in Scheme $2 .{ }^{17}$

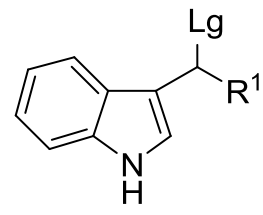

3

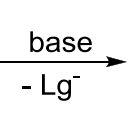<smiles>[R]C=C1C=Nc2ccccc21</smiles>
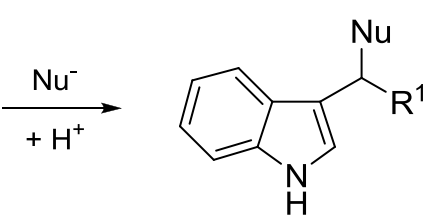

5

Scheme 2. Functionalization of indoles from alkylideneindolenine intermediates 4. 
A suitable leaving group ( $\mathrm{Lg}$ ) located at 'benzylic position' of derivatives $\mathbf{3}$ can be eliminated under basic conditions leading to alkylideneindolenine $\mathbf{4}$ which upon nucleophilic addition leads to functionalized indole $\mathbf{5}$. Among different precursors available for this purpose, 3-(1-arylsulfonylalkyl) indoles 6 (sulfonyl indoles) are those which present better features since are mostly solid compounds stable enough to be easily purified and stored. ${ }^{18}$ Sulfonyl indoles 6 can be readily obtained by a three component coupling of an indole, an aldehyde and $p$-toluenesulfinic acid under acidic conditions (Scheme 3$).{ }^{19}$
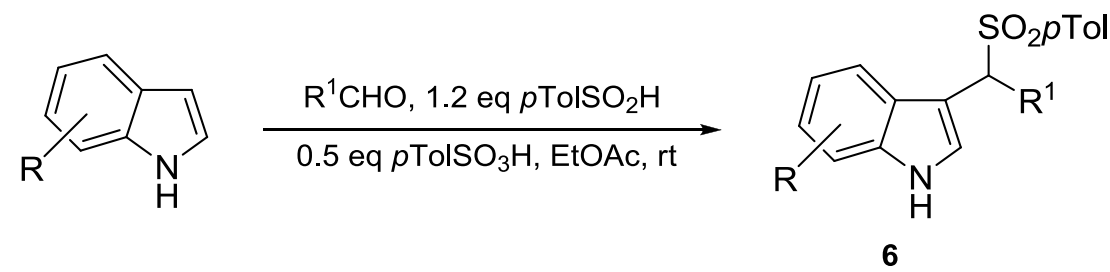

Scheme 3. Synthesis of 3-(1-arylsulfonylalkyl) indoles (sulfonyl indoles) 6.

The arylsulfonyl group in sulfonyl indoles can be eliminated under very mild basic conditions allowing these substrates to be successfully used even in asymmetric synthesis. It should be observed that several nucleophilic reactants currently used in this process are basic enough to warrant the elimination of the arylsulfonyl group of sulfonyl indoles $\mathbf{6}$ avoiding the need of an external base. Particularly, the utilization of hydride donors would allow the direct conversion of sulfonyl indoles into 3-alkylindole derivatives. The effectiveness of lithium aluminiumhydride for this purpose has been evidenced in the early studies focused on the reactivity of sulfonyl indoles but this reagent often lacks of the required selectivity towards other reductable functional groups. ${ }^{20}$ On the other hand, the use of some common reagents usually employed to carry out desulfonylation processes such as tributyltin hydride or $\mathrm{Na} / \mathrm{Hg}$ amalgam is no longer advisable for sustainability reasons. ${ }^{21}$ Sodium borohydride has been successfully employed for the reduction of functionalized sulfonyl indoles aimed at the preparation of tryptophol derivatives, ${ }^{22}$ and unsymmetrical bisindoles. ${ }^{23}$ In these processes the utilization of sodium borohydride entails tedious work up operations, involving solvent consumption and waste production which limit the sustainability of the procedure and often leads to a yield erosion of the obtained products.

In this paper we present a new improved procedure for the preparation of 3-alkylindoles by reduction of sulfonyl indoles under flow chemical conditions using polymer-supported borohydride $\left(\mathrm{PS}^{-} \mathrm{BH}_{4}\right)$ as single reactant. The combination of flow chemistry with the use of a solid supported species reduces the work-up step just to a solvent evaporation, thus decreasing the time process and maximizing the productivity. ${ }^{24-26}$ Furthermore, a new one-pot synthesis of 3-alkylindoles starting from their remote precursors (indoles and aldehydes) has been implemented thanks to the peculiarities of these technologies.

\section{Results and Discussion}

The experimental set up for studying this transformation involves (i) the use of two syringe pumps respectively containing a solution of the appropriate sulfonyl indoles 6 (reservoir A) and the solvent used for pushing the reaction into the line (reservoir B), (ii) a three-ways valve (V) used for connecting and selecting the reservoirs to a (iii) packed bed reactor (R) containing the solid supported borohydride, and (iv) a back pressure regulator set at $2 \mathrm{~atm}$ for maintaining constant the upstream pressure and flow rate. By means of this flow equipment, 
we preliminarily studied, for the conversion of $6 \mathbf{a}$ into $7 \mathbf{7}$, the effect of different reaction parameters such as stoichiometry and concentration of reactants, residence time and solvent (Scheme 4).

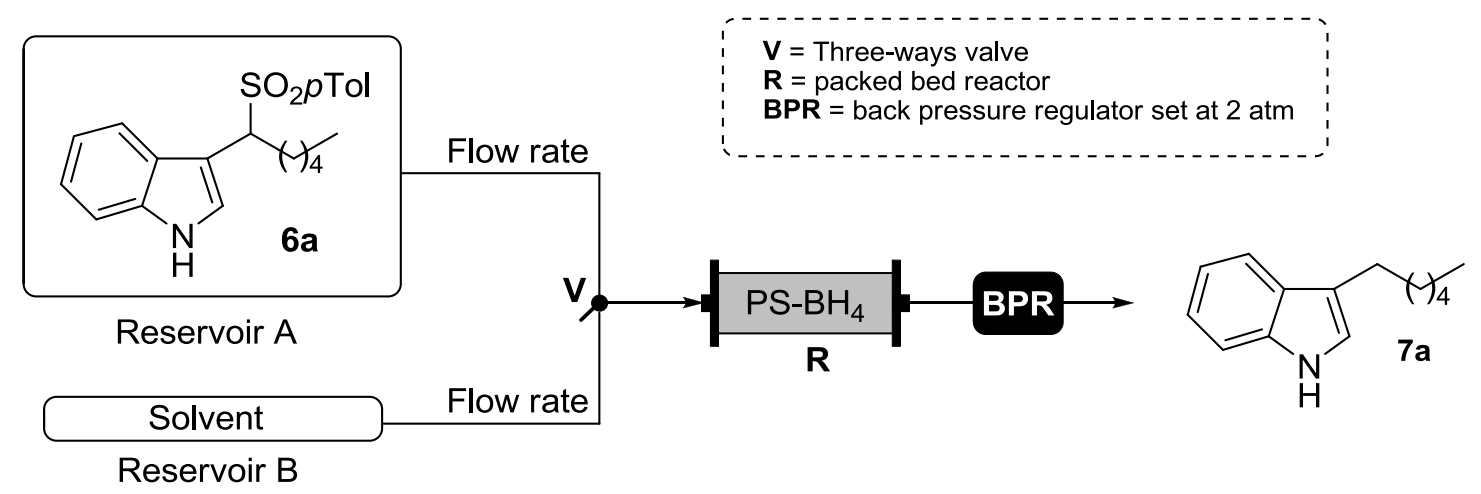

Scheme 4. General apparatus for the reduction of sulfonyl indole 6a to 3-hexylindole 7a.

Firstly, we screened a variety of solvents using 3 equivalents of supported borohydride and a residence time of 45 minutes. Under these conditions the best result was obtained using ethanol (Table 1, entry 7).

Table 1. Optimization studies with various solvents.

\begin{tabular}{llllll}
\hline Entry $^{\mathrm{a}}$ & Solvent (0.03M) & Yield (\%) $^{\mathrm{b}}$ of 7a & Entry $^{\mathrm{a}}$ & Solvent (0.03M) & Yield (\%) $^{\mathrm{b}}$ of 7a \\
\hline 1 & Toluene & - & 6 & $\mathrm{MeCN}$ & $9 \%$ \\
2 & EtOAC & - & 7 & $\mathrm{EtOH}$ & $61 \%$ \\
3 & Dioxane & - & 8 & $\mathrm{MeOH}$ & $54 \%$ \\
4 & $2-\mathrm{MeTHF}_{5}$ & - & 9 & $i-\mathrm{PrOH}$ & $53 \%$ \\
\hline
\end{tabular}

${ }^{\mathrm{a}}$ The reaction was performed using 3 equivalents of $\mathrm{PS}-\mathrm{BH}_{4}$. ${ }^{\mathrm{b}}$ Yield of isolated pure product.

Then, we investigated different ethanolic solutions for the reduction of substrate 6 a observing just a negligible dependence of the chemical yield on the concentration of the substrate (Table 2). Anyway, since the use of a $0.05 \mathrm{M}$ solution appears to provide the best result, this concentration has been selected for the next investigations. More concentrated solutions are poorly applicable because of the reduced solubility of our substrates in ethanol (Table 2, Entry 5).

Table 2. Optimization studies testing different ethanolic concentrations of substrate $\mathbf{6 a}$.

\begin{tabular}{lll}
\hline Entry & Ethanol (Conc. M) & Yield (\%) ${ }^{\text {a of 7a }}$ \\
\hline 1 & 0.03 & 61 \\
2 & 0.04 & 60 \\
3 & 0.02 & 59 \\
4 & 0.05 & 63 \\
5 & 0.06 & ${ }^{c}$ \\
\hline
\end{tabular}

${ }^{\mathrm{a}}$ Conditions: 3 equivalents of $\mathrm{PS}^{-\mathrm{BH}_{4}}$, residence time of $45 \mathrm{~min} .{ }^{\mathrm{b}}$ Yield of isolated pure product. ${ }^{\mathrm{c}}$ Low solubility. 
Finally, we tested various ratios of reducing agent at different flow rates, obtaining the best yield of 7 a (85\%) using 6 equivalents of $\mathrm{PS}^{-\mathrm{BH}_{4}}$ with a residence time of 20 minutes (Table 3, entry 6).

Table 3. Optimization studies testing different amount of $\mathrm{PS}-\mathrm{BH}_{4}$.

\begin{tabular}{llll}
\hline Entry & PS-BH (equiv.) & Residence time $^{\mathrm{a}}$ & Yield (\%) ${ }^{\mathrm{b}}$ of 7a \\
\hline 1 & 3 & $45 \mathrm{~min}$ & 63 \\
2 & 4.5 & $45 \mathrm{~min}$ & 75 \\
3 & 6 & $45 \mathrm{~min}$ & 83 \\
4 & 7.5 & $45 \mathrm{~min}$ & 81 \\
5 & 6 & $30 \mathrm{~min}$ & 84 \\
6 & 6 & $20 \mathrm{~min}$ & 85 \\
7 & 6 & $10 \mathrm{~min}$ & 57 \\
\hline
\end{tabular}

${ }^{\mathrm{a}}$ Substrate concentration $0.05 \mathrm{M} .{ }^{\mathrm{b}}$ Yield of isolated pure product

In order to demonstrate the generality of our method we submitted a series of sulfonyl indoles 6 to the optimized reaction conditions obtaining in all cases good yields even in the presence of sensible functional groups (Scheme 5). The limited solubility of substrates $\mathbf{6 d - g}$ in ethanol required the utilization of 2-MeTHF as a co-solvent for a proper reaction. A solvent ratio EtOH/2-MeTHF 8:2 ensures a viable process although the residence time must be doubled up compared with the ethanol usage.
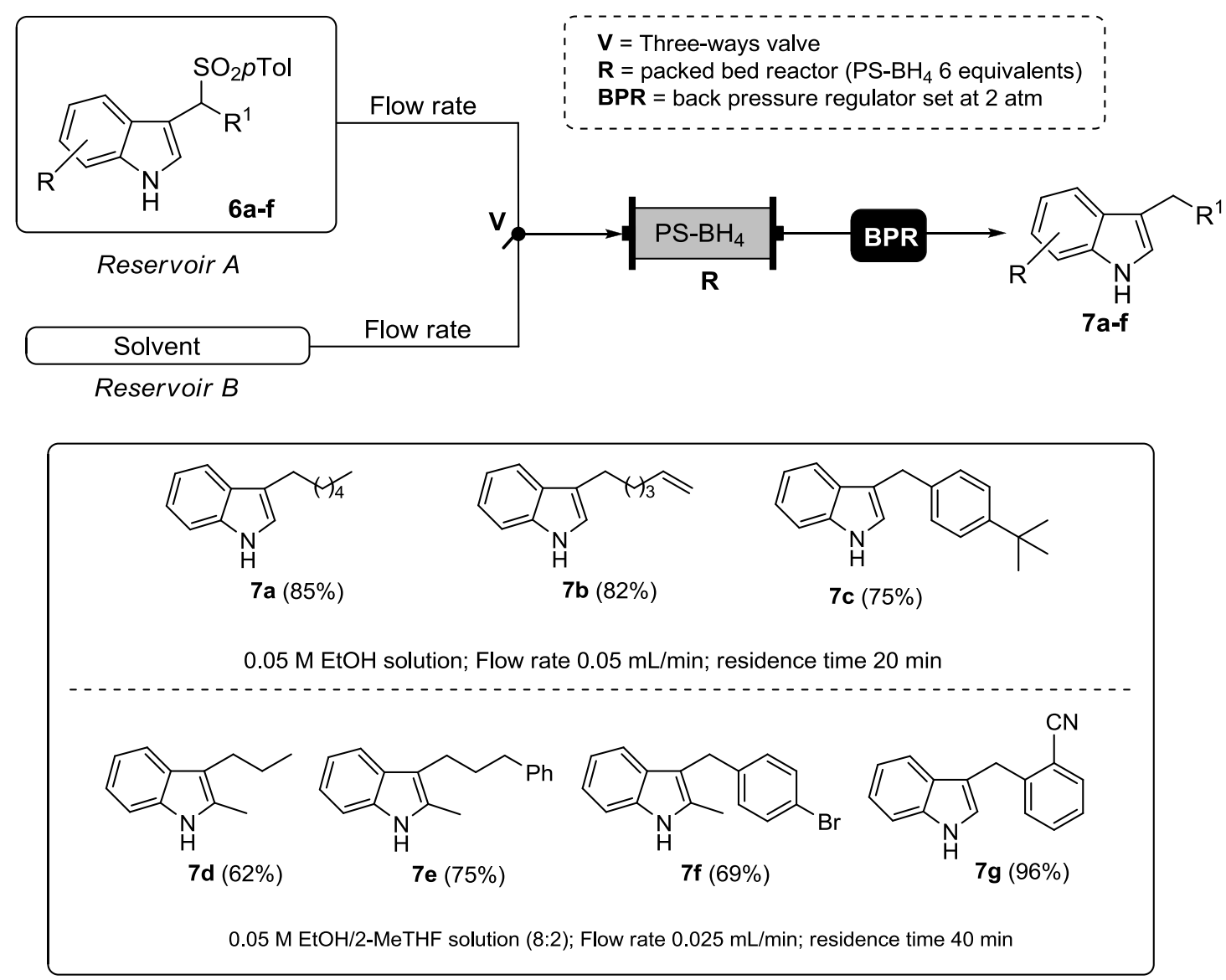

Scheme 5. Reduction of various sulfonyl indoles 6 . 
Finally, the total flow synthesis of three representative compounds $\mathbf{7 h}$-j was undertaken starting from indoles and aldehydes for the generation of 3-alkylindoles in an integrated synthetic operation (Scheme 6). To this aim, we adapted our original batch synthesis of sulfonyl indoles 6 to flow conditions in series with the subsequent reduction step. ${ }^{12}$ As depicted in Scheme 6 , the flow apparatus was made up of four different reservoirs respectively containing the appropriate indole and aldehyde (reservoir $\mathrm{A}$ ), a solution of $p \mathrm{TolSO}_{3} \mathrm{H}$ and $p \mathrm{TolSO}_{2} \mathrm{H}$ (reservoir $\mathrm{B}$ ), ethyl acetate used for pushing the reaction into the line (reservoir $\mathrm{C}$ ), and ethanol, necessary for the reduction step (reservoir D). Additionally, the apparatus was integrated with a coil reactor $\left(\mathbf{R}_{1}\right)$, in which the synthesis of 6 occurs, linked with a further packed bed reactor containing Amberlyst A21 $\left(\mathbf{R}_{\mathbf{2}}\right)$, used as scavenger for the acidic species, a four-ways valve $\left(\mathbf{V}_{\mathbf{1}}\right)$ used for connecting and selecting the reservoirs to the coil reactor, and a T-connector $(\mathbf{T})$ for joining the outgoing flow from $\mathbf{R}_{\mathbf{2}}$ with the reservoir $\mathrm{D}$ and the reactor $\mathbf{R}$. The overall yield recorded for the obtained 3-alkylindoles $\mathbf{7 h}$-j is quite satisfactory considering the two synthetic operations carried out in this approach.

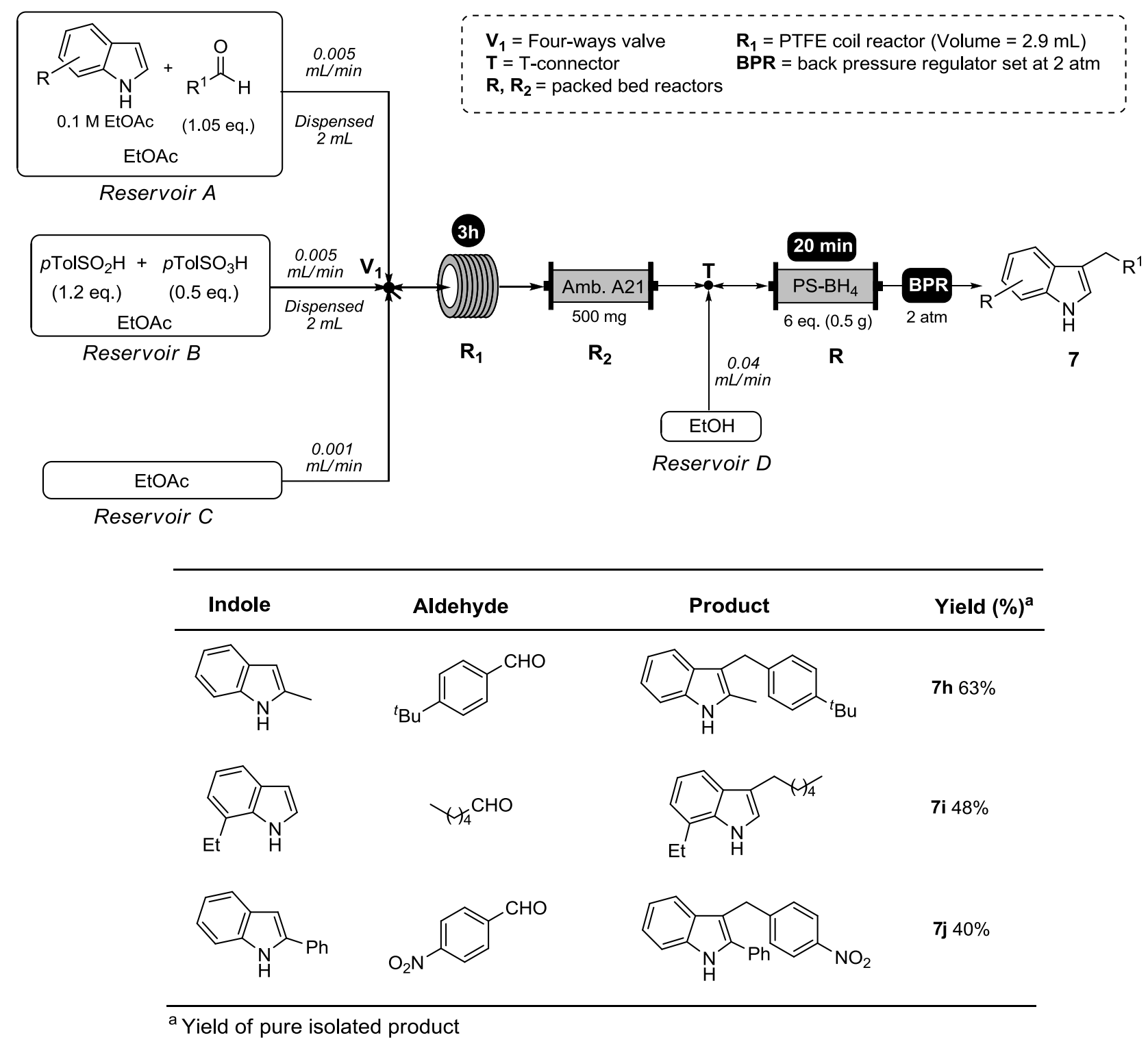

Scheme 6. Synthesis of 3-alkylindoles $7 \mathrm{~h}$-j from their indole and aldehyde remote precursors. 


\section{Conclusions}

The intrinsic difficulty in performing the direct C-3 alkylation of indole systems prompted us to develop a synthetic procedure for the preparation of 3-alkylindoles by reduction of 3-(1-arylsulfonylalkyl) indoles (sulfonyl indoles). In order to increase the sustainability of the process restraining the solvent consumption and work up operations, the flow chemical conditions have been found as the more appropriate for the reduction of sulfonyl indoles using polymer-supported sodium borohydride. Under optimized reaction conditions, various 3 -alkylindoles have been obtained in good yield just after solvent evaporation and column chromatographic separation when required. Since sulfonyl indoles can be obtained by a three component coupling of aldehydes, indoles and arylsulfinic acids, 3-alkylindoles have been also prepared directly starting from these remote precursors embodying sulfonyl indole formation and then reduction in the same flow device. The latter inclusive approach allows the preparation of a set of 3-alylindoles from the corresponding indoles and aldehydes in satisfactory yields with notable waste minimization and reduced solvent consumption.

\section{Experimental Section}

General. ${ }^{1} \mathrm{H}-\mathrm{NMR}$ analyses were recorded at $400 \mathrm{MHz}$ on a Varian Mercury Plus $400 .{ }^{13} \mathrm{C}-\mathrm{NMR}$ analyses were recorded at $100 \mathrm{MHz}$. IR spectra were recorded with a Perkin Elmer FT-IR spectrometer Spectrum Two UATR. Microanalyses were performed with a CHNS-O analyzer Model EA 1108 from Fisons Instruments. GS-MS analyses were obtained by a Hewlett-Packard GC/MS 6890N that works with the El technique (70 eV). Solutions in the flow apparatus were injected using syringe pumps model NE-300 (New Era Pump Systems Inc.). All chemical used are commercially available and were used without further purification. Sulfonyl indoles 6 were prepared according to literature method. ${ }^{19}$

General procedure for the flow reduction of 6 into 7. The flow equipment was set up according to the Scheme 5. The appropriate sulfonyl indole $6 a-c(0.25 \mathrm{mmol})$ was taken up in ethanol $(5 \mathrm{~mL})$ and the corresponding solution was introduced into reservoir $A$, while the reservoir $B$ was filled only with ethanol (10 $\mathrm{mL})$. The solution of the reservoir $A(4 \mathrm{~mL})$ was pumped, with a flow rate of $0.05 \mathrm{~mL} / \mathrm{min}$, into the three-way valve $\mathbf{V}$ and then through the packed bed reactor $\mathbf{R}$ containing $\mathrm{PS}_{-} \mathrm{BH}_{4}$ resin $(1.2 \mathrm{mmol}, 0.53 \mathrm{~g}$, residence time $\sim 20 \mathrm{~min}$ ) and pressurized by a BPR set at $2 \mathrm{~atm}$. When the allotted volume from reservoir $A$ was delivered, the valve $V$ was switched from reservoir $A$ to $B$, and a stream of ethanol $(4 \mathrm{~mL}, 0.05 \mathrm{~mL} / \mathrm{min}$ ) was flowed through the system to push out the residual sulfonyl indole. The outflow was collected in a $25 \mathrm{~mL}$ round bottom flask, the solution was concentrated at reduced pressure and the crude product $7 a-c$ was purified by flash column chromatography on silica gel (hexanes/EtOAc 9:1).

For substrates $6 \mathrm{~d}-\mathrm{g}$ the same procedure was adopted except the solvent used (EtOH/2-MeTHF 8:2) and flow rate of $0.025 \mathrm{~mL} / \mathrm{min}$, residence time of $40 \mathrm{~min}$.

3-Hexyl-1H-indole (7a). ${ }^{27}$ Yellow oil. IR (neat): $3413,2924,2857,1455,738 \mathrm{~cm}^{-1} .{ }^{1} \mathrm{H}-\mathrm{NMR}\left(400 \mathrm{MHz}, \mathrm{CDCl}_{3}\right): \delta$ $0.96(\mathrm{t}, 3 \mathrm{H}, J 7.3 \mathrm{~Hz}), 1.27-1.57(\mathrm{~m}, 6 \mathrm{H}), 1.70-1.85(\mathrm{~m}, 2 \mathrm{H}), 2.81(\mathrm{t}, 2 \mathrm{H}, J 7.7 \mathrm{~Hz}), 6.97(\mathrm{~s}, 1 \mathrm{H}), 7.18(\mathrm{t}, 1 \mathrm{H}, J 7.7$ $\mathrm{Hz}), 7.25(\mathrm{t}, 1 \mathrm{H}, J 7.7 \mathrm{~Hz}), 7.37(\mathrm{~d}, 1 \mathrm{H}, J 7.7 \mathrm{~Hz}), 7.68(\mathrm{~d}, 1 \mathrm{H}, J 7.7 \mathrm{~Hz}), 7.81$ (br s, 1H). ${ }^{13} \mathrm{C}-\mathrm{NMR}(100 \mathrm{MHz}$, $\left.\mathrm{CDCl}_{3}\right): \delta=14.5,23.0,25.5,29.7,30.5,32.1,111.3,117.4,119.3,121.3,122.1,127.9,136.6$. MS (EI): $\mathrm{m} / z(\%)=$ 
201 (44, [ $\left.\left.\mathrm{M}^{+}\right]\right), 130$ (100), 103 (9), 77 (10). Anal. Calcd for $\mathrm{C}_{14} \mathrm{H}_{19} \mathrm{~N}$ (201.31): C, 83.53; H, 9.51; N, 6.96. Found: C, $83.57 ; \mathrm{H}, 9.48 ; \mathrm{N}, 6.99$.

3-(Hex-5-enyl)-1H-indole (7b). Yellow oil. IR (neat): 3415, 2925, 1455, 909, $740 \mathrm{~cm}^{-1} .{ }^{1} \mathrm{H}-\mathrm{NMR}(400 \mathrm{MHz}$, $\left.\mathrm{CDCl}_{3}\right): \delta=1.46-1.56(\mathrm{~m}, 2 \mathrm{H}), 1.69-1.79(\mathrm{~m}, 2 \mathrm{H}), 2.12(\mathrm{q}, 2 \mathrm{H}, J 6.75,8.14 \mathrm{~Hz}), 2.77(\mathrm{t}, 1 \mathrm{H}, J$ 7.54), 4.93-5.05 (m, $2 \mathrm{H}), 5.78-5.89(\mathrm{~m}, 1 \mathrm{H}), 6.98(\mathrm{~s}, 1 \mathrm{H}), 7.10-7.15(\mathrm{~m}, 1 \mathrm{H}), 7.17-7.22(\mathrm{~m}, 1 \mathrm{H}), 7.36(\mathrm{~d}, 1 \mathrm{H}, J 8.11 \mathrm{~Hz}), 7.62(\mathrm{~d}, 1 \mathrm{H}, J$ $8.33 \mathrm{~Hz}), 7.89$ (br s, 1H). ${ }^{13} \mathrm{C}-\mathrm{NMR}\left(100 \mathrm{MHz}, \mathrm{CDCl}_{3}\right): \delta=25.2,29.1,29.9,33.9,111.3,114.6,117.2,119.2$, 119.3, 121.3, 122.1, 127.8, 136.6, 139.3. MS (EI): $m / z$ (\%) = 199 (19, [M $\left.\left.{ }^{+}\right]\right), 156$ (14), 130 (100), 103 (6), 77 (7). Anal. Calcd for $\mathrm{C}_{14} \mathrm{H}_{17} \mathrm{~N}$ (199.30): C, 84.37; H, 8.60; N, 7.03. Found: C, 84.41; H, 8.57; N, 7.05.

3-(4-tert-Butylbenzyl)-1H-indole (7c). ${ }^{28}$ Pale yellow solid, $\mathrm{mp} 124-126^{\circ} \mathrm{C}$. IR (neat): $3404,2960,1455,818,742$ $\mathrm{cm}^{-1} .{ }^{1} \mathrm{H}-\mathrm{NMR}\left(400 \mathrm{MHz} \mathrm{CDCl}_{3}\right): \delta=1.34(\mathrm{~s}, 9 \mathrm{H}), 4.13(\mathrm{~s}, 2 \mathrm{H}), 6.91-6.95(\mathrm{~m}, 1 \mathrm{H}), 7.13(\mathrm{t}, 1 \mathrm{H}, \mathrm{J} 7.7 \mathrm{~Hz}), 7.19-7.28$ $(\mathrm{m}, 3 \mathrm{H}), 7.32-7.39(\mathrm{~m}, 3 \mathrm{H}), 7.60(\mathrm{~d}, 1 \mathrm{H}, \mathrm{J} 8.1 \mathrm{~Hz}), 7.89(\mathrm{br} \mathrm{s}, 1 \mathrm{H}) .{ }^{13} \mathrm{C}-\mathrm{NMR}\left(100 \mathrm{MHz}, \mathrm{CDCl}_{3}\right): \delta=31.2,31.7$, $34.6,111.2,116.2,119.5,119.6,122.3,122.6,125.5,127.8,128.6,136.7,138.4,148.9 . \mathrm{MS}(\mathrm{EI}): \mathrm{m} / \mathrm{z}(\%)=263$ (100, $\left.\left[\mathrm{M}^{+}\right]\right), 244$ (61), 232 (10), 206 (23), 130 (46), 110 (9). Anal. Calcd for $\mathrm{C}_{19} \mathrm{H}_{21} \mathrm{~N}$ (263.38): C, 86.64; H, 8.04; $\mathrm{N}, 5.32$. Found: $\mathrm{C}, 86.68 ; \mathrm{H}, 8.01 ; \mathrm{N}, 5.35$.

2-Methyl-3-propyl-1H-indole (7d). ${ }^{29}$ Pinkish oil. IR (neat): 3404, 2956, 2929, 1459, 1298, $738 \mathrm{~cm}^{-1} .{ }^{1} \mathrm{HNMR}$ $\left(400 \mathrm{MHz}_{\mathrm{CDCl}}\right): \delta=0.95(\mathrm{t}, 3 \mathrm{H}, J 7.3 \mathrm{~Hz}), 1.60-1.72(\mathrm{~m}, 2 \mathrm{H}), 2.37(\mathrm{~s}, 3 \mathrm{H}), 2.68(\mathrm{t}, 2 \mathrm{H}, J 7.3 \mathrm{~Hz}), 7.04-7.14(\mathrm{~m}$, $2 \mathrm{H}), 7.25-7.28(\mathrm{~m}, 1 \mathrm{H}), 7.52(\mathrm{~d}, 1 \mathrm{H}, J 7.3 \mathrm{~Hz}), 7.68$ (br s, $1 \mathrm{H}) .{ }^{13} \mathrm{CNMR}\left(100 \mathrm{MHz}, \mathrm{CDCl}_{3}\right): \delta=11.9,14.3,24.1$, 26.4, 110.3, 112.5, 118.4, 119.2, 121.0, 129.1, 131.0, 135.5. MS (EI): $m / z(\%)=173\left(48,\left[\mathrm{M}^{+}\right]\right), 144(100), 115$ (10), 77 (9). Anal. Calcd for $\mathrm{C}_{12} \mathrm{H}_{15} \mathrm{~N}$ (173.26): C, 83.19; H, 8.73; N, 8.08. Found: C, 83.23; H, 8.70; N, 8.11.

2-Methyl-3-(3-phenylpropyl)-1H-indole (7e). ${ }^{20}$ Pale yellow solid, $\mathrm{mp} 76-79^{\circ} \mathrm{C}$. IR (neat): $3413,3054,2920$, 2848, 1459, 1298, 738, $702 \mathrm{~cm}^{-1} .{ }^{1} \mathrm{H}-\mathrm{NMR}\left(400 \mathrm{MHz}, \mathrm{CDCl}_{3}\right): \delta 1.97-2.08(\mathrm{~m}, 2 \mathrm{H}), 2.36(\mathrm{~s}, 3 \mathrm{H}), 2.73(\mathrm{t}, 2 \mathrm{H}, \mathrm{J} 7.7$ $\mathrm{Hz}), 2.79(\mathrm{t}, 2 \mathrm{H}, \mathrm{J} 7.7 \mathrm{~Hz}), 7.09-7.36(\mathrm{~m}, 8 \mathrm{H}), 7.53(\mathrm{~d}, 1 \mathrm{H}, J 7.3 \mathrm{~Hz}), 7.64(\mathrm{br} \mathrm{s}, 1 \mathrm{H}) .{ }^{13} \mathrm{C}-\mathrm{NMR}\left(100 \mathrm{MHz}^{\mathrm{C} C D C l}\right)_{3}: \delta$ $=12.0,24.1,32.5,36.0,110.4,112.1,118.4,119.3,121.1,125.9,128.5,128.7,129.0,131.1,135.5,142.9$. MS (EI): $m / z(\%)=249\left(72,\left[\mathrm{M}^{+}\right]\right), 144(100), 130(14), 115$ (10), 91 (10), 77 (10). Anal. Calcd for $\mathrm{C}_{18} \mathrm{H}_{19} \mathrm{~N}(249.36): \mathrm{C}$, 86.70; H, 7.68; N, 5.62. Found: C, 86.74; H, 7.71; N, 5.59.

3-(4-Bromobenzyl)-2-methyl-1H-indole (7f). ${ }^{30}$ Pale yellow solid, $\mathrm{mp} 122-125^{\circ} \mathrm{C}$. IR (neat): $3440,2902,1486$, 1459, 1437, 1011, $747 \mathrm{~cm}^{-1} .{ }^{1} \mathrm{H}-\mathrm{NMR}\left(400 \mathrm{MHz}, \mathrm{CDCl}_{3}\right): \delta 2.38(\mathrm{~s}, 3 \mathrm{H}), 4.02(\mathrm{~s}, 2 \mathrm{H}), 7.01-7.16(\mathrm{~m}, 4 \mathrm{H}), 7.29(\mathrm{~d}$, $1 \mathrm{H}$, J 8.1 Hz), 7.34-7.39 (m, 3H), 7.80 (br s, 1H). ${ }^{13} \mathrm{C}-\mathrm{NMR}\left(100 \mathrm{MHz}, \mathrm{CDCl}_{3}\right): \delta=12.0,29.8,110.1,110.5,118.4$, 119.6, 121.4, 128.9, 130.2, 131.5, 132.0, 135.5, 140.9. MS (EI): $m / z$ (\%) = 299 (49), 284 (20), 204 (12), 144 (100), 109 (14), 102 (17). Anal. Calcd for $\mathrm{C}_{16} \mathrm{H}_{14} \mathrm{BrN}$ (300.2): C, 64.02; H, 4.70; N, 4.67. Found: C, 64.06; H, 4.73; $\mathrm{N}, 4.70$.

2-((1H-Indol-3-yl)methyl)benzonitrile (7g). Pale yellow viscous oil. IR (neat): $3411,3063,2225,1455,732 \mathrm{~cm}^{-1}$. ${ }^{1} \mathrm{H}-\mathrm{NMR}\left(400 \mathrm{MHz}, \mathrm{CDCl}_{3}\right): \delta 4.35(\mathrm{~s}, 2 \mathrm{H}), 7.06-7.15(\mathrm{~m}, 2 \mathrm{H}), 7.22(\mathrm{t}, 1 \mathrm{H}, J$ 8.2), $7.27(\mathrm{t}, 1 \mathrm{H}, J$ 6.8), 7.34-7.39 (m, $2 \mathrm{H}), 7.55(\mathrm{~d}, 1 \mathrm{H}, J 8.0 \mathrm{~Hz}), 7.65(\mathrm{~d}, 1 \mathrm{H}, J 7.64 \mathrm{~Hz}), 8.10$ (br s, 1H). ${ }^{13} \mathrm{C}-\mathrm{NMR}\left(100 \mathrm{MHz}, \mathrm{CDCl}_{3}\right): \delta 30.5,111.6$, $112.5,113.4,118.6,119.1,119.9,122.5,123.3,126.8,127.3,130.0,133.1,136.6,145.4 . \mathrm{MS}(\mathrm{EI}): \mathrm{m} / \mathrm{z}(\%)=232$ (100), 204 (10), 130 (75), 102 (10). Anal. Calcd for $\mathrm{C}_{16} \mathrm{H}_{12} \mathrm{~N}_{2}$ (232.29): C, 82.73; H, 5.21; N, 12.06. Found: C, 82.77; H, 5.24; N, 12.04 .

\section{General one-pot procedure for the synthesis of 3-alkylindoles $7 \mathrm{~h}-\mathrm{j}$.}

The flow equipment was set up according to the Scheme 6 . The appropriate indole ( $0.3 \mathrm{mmol})$ and aldehyde $(0.3 \mathrm{mmol})$ were taken up in EtOAc $(3 \mathrm{~mL})$ and then introduced into reservoir $A$. Reservoir $B$ was filled with a solution of $p \mathrm{TolSO}_{3} \mathrm{H} \cdot \mathrm{H}_{2} \mathrm{O}(0.15 \mathrm{mmol}, 28 \mathrm{mg})$ and $p$ TolSO$_{2} \mathrm{H}(0.36 \mathrm{mmol}, 56 \mathrm{mg})$ in EtOAc $(3 \mathrm{~mL})$, while the reservoir $\mathrm{C}$ was filled only with the EtOAc. The two solutions ( $2 \mathrm{~mL}$ each) were simultaneously pumped with a flow rate of $0.005 \mathrm{~mL} / \mathrm{min}$ for each pump into the $\mathbf{V}_{\mathbf{1}}$ four-way valve before passing through a $1.8 \mathrm{~mL}$ coil 
reactor (residence time $3 \mathrm{~h}$ ) and the packed bed reactor $\mathbf{R}_{\mathbf{2}}$ containing $0.5 \mathrm{~g}$ of Amberlyst A21. The outflow stream was subsequently connected by a T-piece mixer (T) with the reservoir $D$ (ethanol, flow rate 0.04 $\mathrm{mL} / \mathrm{min}$ ) and pushed through the packed bed reactor $\mathbf{R}$ containing $\mathrm{PS}_{-} \mathrm{BH}_{4}$ resin $(1.2 \mathrm{mmol}, 0.53 \mathrm{~g}$, residence time $20 \mathrm{~min}$ ). The system was pressurized by a BPR set at 2 atm. Finally, fresh ethyl acetate (reservoir C) was used, by switching the valve $\mathbf{V}_{\mathbf{1}}$ to flow the residual solution through the system. The outflow was collected in a $100 \mathrm{~mL}$ round bottom flask, the solution was concentrated at reduced pressure and the crude product 7 was purified by flash column chromatography.

3-(4-tert-Butylbenzyl)-2-methyl-1H-indole (7h). Pale yellow solid, $\mathrm{mp} 136-138^{\circ} \mathrm{C}$. IR (neat): $3395,2956,1463$, 830, $744 \mathrm{~cm}^{-1} .{ }^{1} \mathrm{H}-\mathrm{NMR}\left(400 \mathrm{MHz}_{\mathrm{CDCl}}\right.$ ): $\delta=1.30(\mathrm{~s}, 9 \mathrm{H}), 2.40(\mathrm{~s}, 3 \mathrm{H}), 4.05(\mathrm{~s}, 2 \mathrm{H}), 7.05(\mathrm{dt}, 1 \mathrm{H}, J 0.8,7.3 \mathrm{~Hz})$, $7.12(\mathrm{dt}, 1 \mathrm{H}, J$ 0.8, $7.3 \mathrm{~Hz}), 7.17(\mathrm{~d}, 2 \mathrm{H}, J 8.1 \mathrm{~Hz}), 7.25-7.30(\mathrm{~m}, 3 \mathrm{H}), 7.44(\mathrm{~d}, 1 \mathrm{H}, J 7.7 \mathrm{~Hz}), 7.75(\mathrm{br} \mathrm{s}, 1 \mathrm{H}) .{ }^{13} \mathrm{C}-$ NMR $\left(100 \mathrm{MHz}_{\mathrm{CDCl}}\right): \delta=12.1,29.8,31.7,34.5,110.4,111.0,118.7,119.4,121.2,125.4,128.1,129.2,131.8$, 135.5, 138.8, 148.6. MS (EI): $m / z(\%)=277\left(100,\left[\mathrm{M}^{+}\right]\right), 262$ (57), $220(14), 144$ (71). Anal. Calcd for $\mathrm{C}_{20} \mathrm{H}_{23} \mathrm{~N}$ (277.41): C, 86.59; H, 8.36; N, 5.05. Found: C, 86.63; H, 8.39; N, 5.08.

7-Ethyl-3-hexyl-1H-indole (7i). Pale yellow oil. IR (neat): 3419, 2929, 1432, 1076, $744 \mathrm{~cm}^{-1} .{ }^{1} \mathrm{H}-\mathrm{NMR}(400 \mathrm{MHz}$, $\left.\mathrm{CDCl}_{3}\right): \delta 0.90(\mathrm{t}, 3 \mathrm{H}, J 7.3 \mathrm{~Hz}), 1.28-1.46(\mathrm{~m}, 9 \mathrm{H}), 1.66-1.77(\mathrm{~m}, 2 \mathrm{H}), 2.75(\mathrm{t}, 2 \mathrm{H}, J 7.7 \mathrm{~Hz}), 2.86(\mathrm{q}, 2 \mathrm{H}, J 7.7 \mathrm{~Hz})$, $6.98(\mathrm{~s}, 1 \mathrm{H}), 7.01-7.12(\mathrm{~m}, 2 \mathrm{H}), 7.48(\mathrm{~d}, 1 \mathrm{H}, \mathrm{J} 7.7 \mathrm{~Hz}), 7.86(\mathrm{br} \mathrm{s}, 1 \mathrm{H}) .{ }^{13} \mathrm{C}-\mathrm{NMR}\left(100 \mathrm{MHz}, \mathrm{CDCl}_{3}\right): \delta 14.1,14.4$, 23.0, 24.3, 25.5, 29.6, 30.4, 32.0, 117.0, 117.9, 119.6, 120.6, 120.8, 126.6, 127.6, 131.4. MS (EI): $\mathrm{m} / \mathrm{z}(\%)=229$ (28, $\left.\left[\mathrm{M}^{+}\right]\right), 158$ (100), 143 (10). Anal. Calcd for $\mathrm{C}_{16} \mathrm{H}_{23} \mathrm{~N}$ (229.37): C, 83.79; H, 10.11; N, 6.11. Found: C, 83.76; H, $10.08 ; \mathrm{N}, 6.08$.

3-(4-Nitrobenzyl)-2-phenyl-1H-indole (7j). Yellow viscous oil. IR (neat): 3407, 3059, 1708, 1597, 1514, 1459, 1340, $732 \mathrm{~cm}^{-1} .{ }^{1} \mathrm{H}-\mathrm{NMR}\left(400 \mathrm{MHz}, \mathrm{CDCl}_{3}\right): \delta 4.36(\mathrm{~s}, 2 \mathrm{H}), 7.10(\mathrm{dt}, 1 \mathrm{H}, J 0.9,8.1 \mathrm{~Hz}), 7.24(\mathrm{dt}, 1 \mathrm{H}, J 0.9,8.1 \mathrm{~Hz})$, 7.33-7.50 (m, 9H), $8.10(\mathrm{~d}, 2 \mathrm{H}, J 8.5 \mathrm{~Hz}), 8.24$ (br s, $1 \mathrm{H}) .{ }^{13} \mathrm{C}-\mathrm{NMR}\left(100 \mathrm{MHz}, \mathrm{CDCl}_{3}\right): \delta=149.7,136.2,132.7$, $129.3,129.2,128.4,128.1,124.0,123.0,120.4,119.3,111.3,109.6,30.8 . \mathrm{MS}(\mathrm{EI}): \mathrm{m} / z(\%)=328\left(100,\left[\mathrm{M}^{+}\right]\right)$, 281 (10), 206 (83), 178 (8). Anal. Calcd for $\mathrm{C}_{21} \mathrm{H}_{16} \mathrm{~N}_{2} \mathrm{O}_{2}$ (328.37): C, 76.81; H, 4.91; N, 8.53. Found: C, 76.85; $\mathrm{H}$, $4.94 ; \mathrm{N}, 8.56$.

\section{Acknowledgements}

The authors thank the University of Camerino for the financial support.

\section{References}

1. Lancianesi, S.; Palmieri, A.; Petrini, M. Chem. Rev. 2014, 114, 7180-7149. https://doi.org/10.1021/cr400676v

2. Bartoli, G.; Bencivenni, G.; Dalpozzo, R. Chem. Soc. Rev. 2010, 39, 4449-4465. https://doi.org/10.1039/b923063g

3. Zeng, M.; You, S.-L. Synlett 2010, 9, 1289-1301.

4. Bandini, M.; Eichholzer, A. Angew. Chem., Int. Ed. 2009, 48, 9608-9644. https://doi.org/10.1002/anie.200901843

5. Bandini, M.; Melloni, A.; Tommasi, S.; Umani-Ronchi, A. Synlett 2005, 8, 1199-1222. https://doi.org/10.1055/s-2005-865210 
6. Joule, J. A.; Mills, K. Heterocyclic Chemistry, $5^{\text {th }}$ Ed. Wiley: New York, 2010

7. Zhu, X.; Ganesan, A. J. Org. Chem. 2002, 67, 2705-2708. https://doi.org/10.1021/jo010996b

8. Tsuchimoto, T.; Kanbara, M. Org. Lett. 2011, 13, 912-915. https://doi.org/10.1021/ol1029673

9. Cadierno, V.; Francos, J.; Gimeno, J. Chem. Commun. 2010, 46, 4175-4177. https://doi.org/10.1039/c002804e

10. Nomiyama, S.; Hondo, T.; Tsuchimoto, T. Adv. Synth. Catal. 2016, 358, 1136-1149. https://doi.org/10.1002/adsc.201500502

11. Rizzo, J. R.; Alt, C. A.; Zhang, T. Y.; Tetrahedron Lett. 2008, 49, 6749-6751. https://doi.org/10.1016/j.tetlet.2008.08.034

12. Putra, A. E.; Takigawa, K.; Tanaka, H.; Ito, Y.; Oe, Y.; Ohta, T. Eur. J. Org. Chem. 2013, 6344-6354. https://doi.org/10.1002/ejoc.201300744

13. Siddiki, S. M. A. H.; Kon, K.; Shimizu, K. Chem. Eur. J. 2013, 19, 14416-14419. https://doi.org/10.1002/chem.201302464

14. Whitney, S.; Grigg, R.; Derrick, A.; Keep, A. Org. Lett. 2007, 9, 3299-3302. https://doi.org/10.1021/ol071274v

15. Han, X.; Wu, J. Angew. Chem. Int. Ed. 2013, 52, 4637-4640. https://doi.org/10.1002/anie.201209810

16. Imm, S.; Bähn, S.; Tillack, A.; Mevius, K.; Neubert, L.; Beller, M. Chem. Eur. J. 2010, 16, 2705-2709. https://doi.org/10.1002/chem.200903261

17. Palmieri, A.; Petrini, M.; Shaikh, R. R. Org. Biomol. Chem. 2010, 8, 1259-1270. https://doi.org/10.1039/B919891A

18. Palmieri, A.; Petrini, M. Chem. Rec. 2016, 16, 1353-1379. https://doi.org/10.1002/tcr.201500291

19. Palmieri, A.; Petrini, M. J. Org. Chem. 2007, 72, 1863-1866. https://doi.org/10.1021/jo062538e

20. Ballini, R.; Palmieri, A.; Petrini, M.; Torregiani, E. Org. Lett. 2006, 8, 4093-4096. https://doi.org/10.1021/ol061604w

21. Nájera, C.; Yus, M. Tetrahedron 1999, 55, 10547-10568. https://doi.org/10.1016/S0040-4020(99)00600-6

22. Palmieri, A.; Petrini, M. Org. Biomol. Chem. 2012, 10, 3486-3493. https://doi.org/10.1039/c2ob25056j

23. Lancianesi, S.; Palmieri, A.; Petrini, M. Adv. Synth. Catal. 2012, 354, 3539-3544. https://doi.org/10.1002/adsc.201200632

24. Pastre, J. C.; Browne, D. L.; Ley, S. V. Chem. Soc. Rev. 2013, 42, 8849-8869. https://doi.org/10.1039/c3cs60246j

25. Baumann, M.; Baxendale, I. R. Beilstein J. Org. Chem. 2015, 11, 1194-1219. https://doi.org/10.3762/bjoc.11.134

26. Glasnov, T. Continuous-Flow Chemistry in the Research Laboratory: Modern Organic Chemistry in Dedicated Reactors at the Dawn of the 21st Century, Springer: Cham, 1st Ed, 2016. https://doi.org/10.1007/978-3-319-32196-7

27. Jia, Y; Zhu, J. J. Org. Chem. 2006, 71, 7826-7834. https://doi.org/10.1021/jo061471s 
28. Siddiki, S. M. A. H.; Kon, K.; Shimizu, K. Chem. Eur. J. 2013, 19, 14416-14419. https://doi.org/10.1002/chem.201302464

29. Patil, N. T.; Konala, A. Eur. J. Org. Chem. 2010, 6831-6839. https://doi.org/10.1002/ejoc.201001114

30. Seck, C.; Mbaye, M. D.; Gaillard, S.; Renaud, J.-L. Adv. Synth. Catal. 2018, 360, 4640-4645. https://doi.org/10.1002/adsc.201800924 